ra rằng phần lớn các triệu chứng của trẻ đều xoay quanh việc học, việc làm bài tập về nhà là rất khó khan do nhiều lí do để né tránh như đi vệ sinh, gọt bút chì, cũng chính vì không tập trung trong việc học trẻ hay đánh mất và quển đồ dùng học tập của mình [7].

\section{KẾT LUẬN}

Qua nghiên cứu 85 trẻ được chẩn đoán ADHD nhận thấy: rối loạn chủ yếu gặp ở nam giới. Tuổi chẩn đoán hay gặp ở nhóm tuổi 6-10 tuổi. Triệu chứng dễ bị sao nhãng bởi các kích thích bển ngoài chiếm tỷ lệ cao nhất, trẻ dễ dàng bị kích thích bởi âm thanh. Mặc dù trẻ gặp khó khăn trong việc duy trì sự chú ý trong các nhiệm vụ nhưng trẻ lại có khả năng tập trung vào thứ mình thích. Trẻ đa phần né tránh việc học, đánh mất đồ dùng học tập, quên đồ dùng học tập.

TÀl LIỆU THAM KHẢO

1. Thomas R., Sanders S., Doust J. và cộng sự.
(2015). Prevalence of attention-deficit/ hyperactivity disorder: a systematic review and meta-analysis. Pediatrics, 135(4), e994-1001.

2. (2013), Diagnostic and statistical manual of mental disorders: DSM-5 ${ }^{\mathrm{TM}}$, 5th ed, American Psychiatric Publishing, Inc., Arlington, VA, US.

3. Martin A., Volkmar F.R., và Bloch M.H. (2017), Lewis's Child and Adolescent Psychiatry: A Comprehensive Textbook, Wolters Kluwer Health.

4. Nøvik T.S., Hervas A., Ralston S.J. và cộng sứ. (2006). Influence of gender on attentiondeficit/hyperactivity disorder in Europe--ADORE. Eur Child Adolesc Psychiatry, 15 Suppl 1, I15-24.

5. Riddle M.A., Yershova K., Lazzaretto D. và cộng sự. (2013). The Preschool AttentionDeficit/Hyperactivity Disorder Treatment Study (PATS) 6-year follow-up. ] Am Acad Child Adolesc Psychiatry, 52(3), 264-278.e2.

6. Silk T.J., Malpas C.B., Beare R. và cộng sự. (2019). A network analysis approach to ADHD symptoms: More than the sum of its parts. PLOS ONE, 14(1), e0211053.

7. Kewley G. (2006), Attention Deficit Hyperactivity Disorder: What Can Teachers Do?, Routledge, London.

\title{
TẮC RUộT QUAI ĐÓNG: GIÁ TRỊ CHẨN ĐOÁN CỦA CẮT LỚP VI TÍNH ĐA DÃY
}

\section{TÓM TẮT.}

Mục tiêu: đánh giá giá trị của cắt lớp vi tính (CLVT) đa dãy trong chẩn đoán tắc ruột quai đóng (TRQĐ). Phương pháp: 145 bệnh nhân tắc ruột trong đó có 40 bệnh nhân TRQĐ được xác định bằng phẩu thuật đã được chụp CLVT có tiêm thuốc cản quang trước mổ tại bệnh viện Việt Đức từ tháng 7/2019 đến tháng 4/2021. Hai bác š̃ chẩn đoán hình ảnh không biết trước kết quả phâ̂u thuật xem phim CLVT và đánh giá 11 dấu hiệu trên CLVT. Từ đó đánh giá độ nhạy, độ đặc hiệu, giá trị dự đoán dương tính và giá tri dự đoán âm tính của từng dấu hiệu. Kết quá: Chẩn đoán TRQĐ, dấu hiệu có ít nhất hai điểm chuyển tiếp có độ nhạy $100 \%$, độ đặc hiệu $97,1 \%$. Dâu hiệu mỏ chim có độ nhạy $87,5 \%$, độ đặc hiệu $66,7 \%$. Dâu hiệu quai ruột hình chữ $U /$ chữ $C$, quai ruột giãn nằm ở vị trí bất thường trong ổ bưng có đô đặc hiêu $100 \%$ và độ nhạy tương ứng là $32,5 \%$ và $15 \%$.Chấn đoán biến chứng thiếu máu thành ruột, dấu hiêuu thành ruột ngấm thuốc kém có độ nhạy $62 \%$, độ đặc hiệu $94,7 \%$; mạch máu mạc treo ngấm

\footnotetext{
${ }^{1}$ Trường Đại học Y Hà Nội

²Bệnh viện Hữu nghi Việt Đức

Chịu trách nhiệm chính: Phạm Thị Thoa

Email: drphamthithoa@gmail.com

Ngày nhận bài: 2.8.2021

Ngày phản biện khoa học: 30.9 .2021

Ngày duyệt bài: 7.10.2021
}

thuốc kém có độ nhạy 23,8\%, độ đặc hiệu 100\%. Kết luâan: ở những bệnh nhân được khảo sát của chúng tôi, có ít nhất hai điểm chuyển tiếp, quai ruột chữ $U / C$, quai ruột giãn ở vị trí bất thường trong ổ bụng có giá trị cao trong chẩn đoán TRQĐ. Sự giảm ngấm thuốc thành ruột và mạch máu mạc treo tương ứng là dấu hiệu gợi ỳ tốt cho thiếu máu ruột. vi tính.

Tư khóa: tắc ruột, quai đóng, thiếu máu, cắt lớp

\section{SUMMARY \\ CLOSED - LOOP BOWEL OBSTRUCTION: DIAGNOSIS VALUE OF \\ MULTISLICECOMPUTED TOMOGRAPHY}

Purpose: The aim of this study was to determine the value of multislice computed tomography (MSCT) in the diagnosis of closed - loop bowel obstruction (CLBO). Methods: 145 patients with bowel obstruction, including 40 patients with CLBOconfirmed by surgery, had preoperated contrast enhancement CT (CECT) at Viet Duc hospital from July 2019 to April 2021. Two blinded radiologists retrospectively reviewed CECT and evaluated 11 CT findings. The sensitivity, specificity, positive predictive value and negative predictive value of each finding was evaluated. Results: Diagnosis of CLBO, at least two transition points has sensitivityof $100 \%$, specificity of $97.1 \%$. Beak sign has sensitivity of $87.5 \%$, specificity of $66.7 \%$. U/C shape configuration, dilated bowel loop in an abnormal position in the abdomen have specificities of $100 \%$ and sensitivities of $32.5 \%$ and 
$15 \%$, respectively. Diagnosis of complications of intestinal ischemia, reduced bowel-wall enhancement has sensitivity of $62 \%$, specificity of $94.7 \%$; reduced enhancement of the mesenteric vein has sensitivity of $23.8 \%$, specificity of $100 \%$. Conclusion: In our prospective, at least two transition points, U/C shape configuration, dilated bowel loop in an abnormal position in the abdomenhave high values in the diagnosis of CLBO. Reduced enhancement of bowel wall and mesenteric vein were good indicators of intestinal ischemia.

Key words: intestinal obstruction, closed loop, ischemia, computed tomography.

\section{I. ĐĂT VẤN ĐỀ}

Tắc ruột là một cấp cứu ngoại khoa phổ biến, chiếm tới $20 \%$ các trường hợp vào viện vì đau bụng cấp, chỉ đứng sau viêm ruột thừa. Tắc ruột được định nghĩa là hội chứng ngừng lưu thông của hơi, dịch và các chất có trong lòng ruột, bao gồm tắc ruột cơ năng và tắc ruột cơ giới ${ }^{1}$. Trong tắc ruột cơ giới chia ra hai nhóm theo cơ chế tắc là tắc ruột do bít và tắc ruột do thắt. Tắc ruột do thắt, ngoài tắc ở lòng ruột, còn tắcở mạch máu mạc treo. Tắc ruột quai đóng là một thể lâm sàng của tắc ruột do thắt, xảy ra khi quai ruột bị tắc ở ít nhất hai điểm nằm gần nhau tạo thành một vòng khép kín ${ }^{2}$, bao gồm: xoắn ruột, tắc ruột trong thoát vị, tắc ruột do dây chằng chẹn ngang quai ruột và mạc treo tương ứng ${ }^{3}$.

Tắc ruột quai đóng thường diễn tiến thiếu máu ruột và hoại tử ruột nhanh, biến chứng ngoại khoa nặng nề nếu chẩn đoán chậm trễ.Tỷ lệ tử vong do tắc ruột quai đóng lên đến $35 \%$ nếu chẩn đoán muộn sau $36 h^{4}$. Vì vậy việc đánh giá nhanh, chính xác tắc ruột quai đóng là rất quan trọng. Tuy nhiên, chẩn đoán trên lâm sàng thường khó khăn. Do đó, vai trò của hình ảnh học trong chuẩn đoán tắc ruột quai đóng là rất quan trong.

Trong khoảng hai thập kỷ trở lại đây, cắt lớp vi tính (CLVT) đã được xem như là phương tiện chẩn đoán hình ảnh hàng đầu trong tắc ruột. Bởi sự nhanh chóng cùng độ chính xác cao, cắt lớp vi tính có khả năng trả lời hầu hết các câu hỏi mà bác sĩ lâm sàng cần ở một bệnh nhân đau bụng cấp nghi ngờ tắc ruột. Đặc biệt với CLVT đa dãy đầu thu cùng các kỹ thuật tái tạo hình ảnh (tái tạo đa mặt phẳng, tái tạo thể tích...), cho phép phẫu thuật viên có thể định hình khu vực cần can thiệp để định hướng phẫu thuật, hạn chế những sai sót có thể ảnh hưởng tới kết quả điều trị, góp phần mang lại kết quả cao nhất, hạn chế tai biến. Các báo cáo của Balthazar ${ }^{2}$ và Makar ${ }^{5}$ đã cho thấy CLVT có vai trò chính trong nhận biết tắc ruột quai đóng, chỉ ra các dấu hiệu hình ảnh thường gặp gợi ý tắc ruột quai đóng. Tuy nhiên, chưa có nghiên cứu nào đánh giá giá trị của những dấu hiệu trên CLVT trong chẩn đoán tắc ruột quai đóng. Ở Việt Nam, hiện chưa có nghiên cứu đầy đủ về các các dấu hiệu nhận biết tắc ruột quai đóng trên CLVT cũng như dự báo biến chứng thiếu máu ruột và hoại tử ruột của tắc ruột quai đóng. Vì vậy chúng tôi tiến hành nghiên cứunày nhằm đánh giá trị của CLVT đa dãy trong chẩn đoán xác định và biến chứng của tắc ruột quai đóng.

\section{II. ĐỐI TƯƠ'NG VÀ PHƯƠNG PHÁP NGHIÊN CỨU}

Đối tượng nghiên cứu. Nghiên cứu được tiến hành trên 40 bệnh nhân tắc ruột quai đóng được chẩn đoán xác định bởi phẫu thuật, được chụp CLVT có tiêm thuốc trước phẫu thuất. Tắc ruột quai đóng bao gồm tắc ruột do xoắn mạc treo ruột, tắc ruột do thoát vị (trừ thoát vị Richter) và tắc ruột do dây chằng chẹn qua hai đâu của một đoạn ruột ${ }^{3}$

Kĩ thuật chụp CLVT. Thăm khám được thực hiện trên máy CLVT 16 dãy (Optima 2019, GE Healthcare System, Milwaukee, WI, USA) với thông số kỹ thuật bao gồm: kV 120, mAs 350, độ dày lớp cắt $5 \mathrm{~mm}$, tái tạo $0,625 \mathrm{~mm}$, trường thăm khám từ vòm hoành đến khớp mu. Tất cả bệnh nhân được sử dụng thuốc cản quang loại tan trong nước là Xenetix $100 \mathrm{ml} / 350 \mathrm{mg}$ (Guerbet, Villepint, France), liêu $1,5 \mathrm{ml} / \mathrm{kg}$, bơm tiêm máy, tốc độ tiêm $5 \mathrm{ml} / \mathrm{giây}$. Các lớp cắt thực hiện thời điểm trước tiêm và sau tiêm thuốc cản quang: thì động mạch thực hiện ở thời điểm 3035 giây, thì tînh mạch cửa thực hiện ở thời điểm 60-70 giây sau khi tiêm thuốc cản quang. Hình ảnh sau đó được tái tạo đa bình diện (axial, coronal và sagittal) và được chuyển qua hế thống PACS INFINIT.

Phân tích hình ảnh. Các dấu hiệu CLVT chẩn đoán tắc ruột quai đóng bao gồm: (1) có ít nhất hai điểm chuyển tiếp (hình 1.A), (2) quai ruột hình chữ U/ chũ̃ C (Hình 1.B), (3) Dấu hiệu "vành tia" hay phân bố dạng ly tâm của quai ruột và mạch máu mạc treo hội tụ về điểm chuyển tiếp(Hình 1.C), (4) Dấu hiệu mỏ chim (Hình 1.D), (5) Dâu hiệu cuộn xoáy (Hình 1.E), (6) Dấu hiệu quai ruột giãn nằm ở vị trí bất thường trong ổ bụng, (7) Dấu hiệu quai ruột giãn nằm ngoài thành bụng(Hình 1.F)

Chẩn đoán biến chứng thiếu máu hay hoại tử ruột trong tắc ruột quai đóng dựa vào các dấu hiệu: thành ruột dày $>2 \mathrm{~mm}$ ở quai ruột giãn; mạch máu mạc treo ngấm thuốc kém; thành ruột ngấm thuốc hình bia; thành ruột ngấm 
thuốc kém ${ }^{6}$.
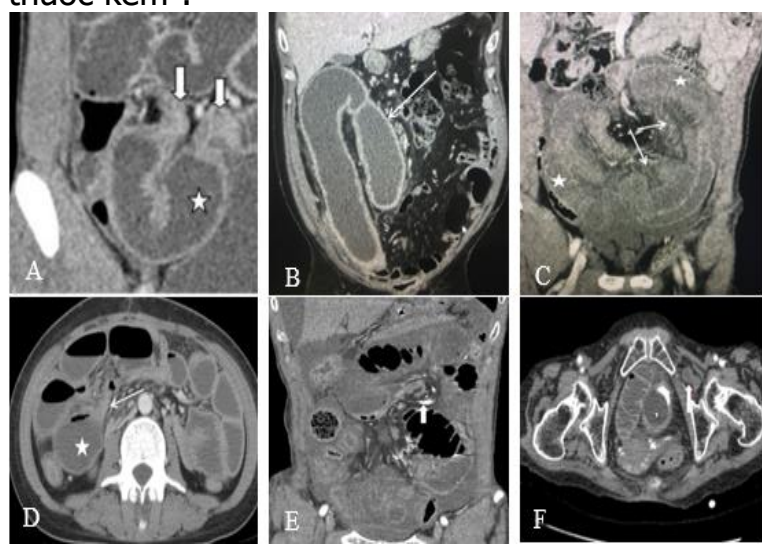

Hình 1. Các dấu hiệu gợi ý tắc ruột quai đóng trên CLVT

Hình A: quai ruột giãn dạng chũ̃ C (ngôi sao) với hai điểm chuyển tiếp (mũi tên) ở bệnh nhân nam, 67 tuổi, TRQĐ do dây chằng.

Hình B: quai ruột hình chữ U (mũi tên) ở bệnh nhân nữ 68 tuổi, TRQĐ do dây chằng.

Hình C: hình ảnh các quai ruột non giãn (ngôi sao) và mạch máu mạc treo (mũi tên) phân bố dạng "vành tia" ở bênh nhân nam, 65 tuổi, xoắn ruột.

Hình D: quai ruột giãn (ngôi sao) hẹp đột ngột tạo hình ảnh giống mỏ chim (mũi tên), bệnh nhân nữ, 27 tuổi, thoát vị nội.

Hình E: Dấu hiệu cuộn xoáy (mũi tên) ở bệnh nhân nam 69 tuổi, xoắn ruột.

Hinh F: quai ruột non nằm vùng đùi trái (mũi tên), bênh nhân nữ, 88 tuổi, thoát vị bit.

Xử lý và phân tích số liệu. Số liệu được nhập và phân tích bằng phần mềm SPSS 20.0
(SPSS, Inc., Chicago, Iillinois, Hoa kỳ). Các biến được trình bày dưới dạng số và tỷ lẹ phần trăm.

Giá trị của CLVT trong chẩn đoán xác định và chẩn đoán biến chứng của tắc ruột quai đóng được xác định bằng độ nhạy, độ đặc hiệu, giá trị dự đoán dương tính, giá trị dự đoán âm tính với kết quả phẫu thuật là tiêu chuẩn vàng.

\section{KẾT QUẢ NGHIÊN CứU}

Từ 7/2019 đến 4/2021, 40 bệnh nhân tắc ruột quai đóng (với 16 nữ và 24 nam, từ 21 - 89

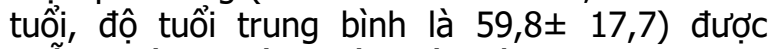
phẫu thuật tại Bệnh viện Việt Đức.

Các nguyên nhân gây tắc ruột quai đóng được trình bày ở bảng 1 . Nguyền nhân gặp nhiều nhất là do dây chằng $(37,5 \%)$, tiếp theo là do xoắn ruột $(30 \%)$, thoát vị nội $(17,5 \%)$ và thoát vị ngoại (15\%).

Bảng 1. Nguyên nhân gây tắc ruột quai đóng trên phâuu thuật

\begin{tabular}{|c|c|c|}
\hline Nguyên nhân & $\begin{array}{c}\text { Số lượng } \\
(\mathbf{n = 4 0 )}\end{array}$ & Tỷ lệ \\
\hline Dây chằng & 15 & $37,5 \%$ \\
\hline Xoắn ruột & 12 & $30 \%$ \\
\hline Thoát vị ngoại & 6 & $15 \%$ \\
\hline Thoát vị nội & 7 & $17,5 \%$ \\
\hline
\end{tabular}

Bảng 2 thể hiện giá trị của các dấu hiệu trên CLVT gợi ý tắc ruột quai đóng. Dâu hiệu có ít nhất hai điểm chuyển tiếp có độ nhay $100 \%$, độ đặc hiệu $97,1 \%$. Dâu hiệu mỏ chim có độ nhạy $87,5 \%$, độ đặc hiệu $66,7 \%$. Dấu hiệu quai ruột hình chữ U/ chữ $\mathrm{C}$, quai ruột giãn nằm ở vị trí bất thường trong ố bụng có độ đặc hiệu $100 \%$; độ nhạy tương ứng lần lượt là $32,5 \%$ và̀ $15 \%$.

Bảng 2. Giá trị của các dấu hiệu CLVT gợi ý tắc ruột quai đóng

\begin{tabular}{|c|c|c|c|c|}
\hline Dấu hiệu CLVT & Độ nhạy & Độ đặc hiệu & PPV & NPV \\
\hline Có ít nhất hai điểm chuyển tiếp & $100 \%$ & $97,1 \%$ & $93 \%$ & $100 \%$ \\
\hline Quai ruột hình chữ U/ chữ C & $32.5 \%$ & $100 \%$ & $100 \%$ & $79,5 \%$ \\
\hline Dấu hiệu "vành tia" & $52,5 \%$ & $94,3 \%$ & $77,8 \%$ & $83,9 \%$ \\
\hline Dấu hiệu cuộn xoáy & $22,5 \%$ & $98,1 \%$ & $81,8 \%$ & $76,9 \%$ \\
\hline Quai ruột giânn nằm ngoài thành bụng & $15 \%$ & $99 \%$ & $85,7 \%$ & $75,4 \%$ \\
\hline $\begin{array}{c}\text { Quai ruột giã̃n nằm ở vị trí bất thường } \\
\text { trong ổ bụng }\end{array}$ & $10 \%$ & $100 \%$ & $100 \%$ & $74,5 \%$ \\
\hline Dấu hiệu mỏ chim & $87,5 \%$ & $66,7 \%$ & $50 \%$ & $94,3 \%$ \\
\hline
\end{tabular}

Bảng 3 thể hiện giá trị của CLVT đa dãy trong chẩn đoán biến chứng tắc ruột quai đóng. Với chẩn đoán những dấu hiệu liên quan đến thiếu máu hoặc hoại tử ruột, hình ảnh thành ruột ngấm thuốc kém có độ nhạy là $62 \%$, độ đặc hiệu là $94,7 \%$ và hình ảnh mạch máu mạc treo ngấm thuốc kém có độ nhạy là $23,8 \%$, độ đặc hiệu là $100 \%$.

Bảng 3. Giá trị của CLVT trong chẩn đoán biến chứng thiếu máu/ hoại tử ruột trong tắc ruột quai đóng.

\begin{tabular}{|c|c|c|c|c|}
\hline Dấu hiệu CLVT & Độ nhạy & Độ đặc hiệu & PPV & NPV \\
\hline Thành ruột dày > 2mm ở quai ruột giãn & $71,4 \%$ & $42,1 \%$ & $57,6 \%$ & $57,1 \%$ \\
\hline Mạch máu mạc treo ngấm thuốc kém & $23,8 \%$ & $100 \%$ & $100 \%$ & $54,3 \%$ \\
\hline
\end{tabular}


VIETNAM MEDICAL JOURNAL N²2 - OCTOBER - 2021

\begin{tabular}{|c|c|c|c|c|}
\hline Thành ruột ngấm thuốc hình bia & $57 \%$ & $73,7 \%$ & $70,6 \%$ & $60,9 \%$ \\
\hline Thành ruột ngấm thuốc kém & $62 \%$ & $94,7 \%$ & $92,8 \%$ & $69,2 \%$ \\
\hline
\end{tabular}

\section{BÀN LUẬN}

Tắc ruột quai đóng thường diễn tiến thiếu máu ruột và hoại tử ruột nhanh nhưng khó nhận biết trên lâm sàng và thường chỉ được xác định khi phẫu thuật. Trong nghiên cứu của chúng tôi, tắc ruột quai đóng chủ yếu xảy ra ở người lớn $(21-89)$, trong đó nam chiếm $60 \%$ (24 BN), nữ chiếm $40 \%(16 \mathrm{BN})$, tỷ lệ nam/nữ = 1,5. Tỷ lệ này phù hợp với các nghiên cứu trước ${ }^{7}$. Nhóm tắc ruột quai đóng chiếm tỷ lệ 27,6\% (40/145) tổng số bệnh nhân tắc ruột tương đồng với kết quả của tác giả Makar ${ }^{5}$ là $27 \%$.

Các dấu hiệu gợi ý tắc ruột quai đóng trên CLVT, dấu hiệu quai ruột chữ $\mathrm{U} /$ chữ $\mathrm{C}$ có độ nhạy, độ đặc hiệu là $32.5 \%$ và $100 \%$. Độ nhạy trong nghiển cứu của chúng tôi cũng tương đương với tác giả Balthazar ${ }^{2}$ là $31,6 \%$. Nguyên nhân chủ yếu làm cho độ nhạy của dấu hiệu này thấp là do độ dài củaquai ruột đóng. Nếu quai đóng ngắn vừa phải, sẽ tạo ra dạng quai đóng chữ $C$ haychữ $U$, nhưng nếu quai đóng quá dài sẽ bị gập góc, làm mất hình dạng đặc trưngnày, một số trường hợp quai đóng quá ngắn cũng không thể tạo được hình dạngchữ $C$ hay chữ U. Dấu hiệu "vành tia" hay phân bố dạng ly tâm của các quai ruột và mạch máu mạc treo trong nghiên cứu của chúng tôi có độ nhạy, độ đặc hiệu $52.5 \%$ và $94.3 \%$ trong chẩn đoán tắc ruột quai đóng. Theo nghiên cứu của Balthazar ${ }^{2}$ thì dấu hiệu này có độ nhạy42,1\%. Dấu hiệu "vành

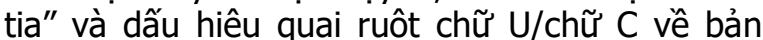
chất là giống nhau nhưng biểuhiên hình dạng khác nhau do độ dài của quai ruột đóng khác nhau.Dấu hiệu mỏ chim có độ nhạy và độ đặc hiệu lần lượt là $87.5 \%, 66.7 \%$. Theo nghiên cứu của Makar ${ }^{5}$ đây là dấu hiệu có giá trị nhất trong chẩn đoán tắc ruột quai đóng. Còn theo tác giả Millet ${ }^{8}$, khi tắc ruột không có dấu hiệu mỏ chim thìđiều trị nội khoa có hiệu quả cao. Ngược lại, khi có nhiều hơn hay bằng 2 dấuhiệu mỏ chim và tắc ruột hoàn toàn thì điêuu trị nội khoa thường thất bại. Độ nhạy, độ đặc hiệu của dấu hiêuu có ít nhất hai điểm chuyển trong chẩn đoán tắc ruột quai đóng là $100 \%$ và $97,1 \%$. Theo tác giả Balthazar², độ nhạy của dâu hiệu này là $36,8 \%$. Độ nhạ trong nghiên cứu của chúng tôi cao hơn có thể giải thích do thời gian hai nghiên cứu cách nhau gần 30 năm, hiện nay với các thế hệ máy CLVT mới đa dãy đâu thu có thể tái tạo đa mặt phẳng giúp việc tìm điểm chuyển tiếp được dễ dàng và chính xác hơn.Nghiên cứu của Millet ${ }^{8}$ kết luận khi tắc ruột có nhiều điểm chuyển tiếp, điều trị nội khoa thất bại với độ đặchiệu 88,5\%. Điều này gián tiếp nói đến việc điều trị nội khoa thất bại ở nhữngbệnh nhân có tắc ruột quai đóng. Dấu hiệu cuộn xoáy có độ nhạy và độ đặc hiệu trong chẩn đoán tắc ruột quai đóng là $22,5 \%$ và $98.1 \%$. Độ nhạy của dấu hiệu này trong nghiên cứu của chúng tôi cao hơn sovới nghiên cứu của Nakashima ${ }^{6}$ là $11,4 \%$ và Balthazar ${ }^{2}$ là $10,5 \%$. Dấuhiệu cuộn xoáy thường gợi ý nguyên nhân gây tắc ruột là xoắn ruột. Trong nghiên cứu của chúng tôi, tỷ lệ xoắn ruột cao hơn trong nghiên cứu của các tác giả trên do đó dấu hiệu cuộn xoáy được quan sát thấy nhiều hơn. Dấu hiệu quai ruột giãn nằm ngoài thành bụng và quai ruột giãn nằm ở vị trí bất thường trong ổ bunng có độ nhạy và độ đặc hiêu lần lượt là $15 \%, 99 \%$ và $10 \%, 100 \%$. Đây là các dấu hiệu chỉ điểm cho tắc ruột quai đóng do thoát vị (thoát vị nội và thoát vị ngoại).

Nguyên nhân gây tắc ruột quai đóng nhiều nhất trong nghiên cứu của chúng tôi là do dây chằng chiếm $37,5 \%$, tiếp theo là xoắn ruột chiếm $30 \%$. Nghiên cứu của Maglinte và cộng sự ${ }^{3}$ cũng đưa ra kết luận dây chằng là nguyên nhân phổ biến nhất của tắc ruột quai đóng. Còn theo tác giả Makar 5 , xoắn ruột là nguyên nhân gây ra $50 \%$ tắc ruột quai đóng, nguyên nhân do dây chằng chỉ chiếm $29 \%$.

Biến chứng nặng nhất trong tắc ruột đó là thiếu máu thành ruột. Trong nghiên cứu của chúng tôi, thành ruột ngấm thuốc kém tương ứng với biến chứng thiếu máu/ hoại tử thành ruột với độ nhạy là $62 \%$ và độ đặc hiệu là $94,7 \%$. Kết quả này phù hợp với kết quả nghiên cứu của Nakashima ${ }^{6}$ với độ nhạy, độ đặc hiệu lần lượt là 67\%; 100\%nhưng độ nhạy cao hớn so với nghiên cứu của $\mathrm{Ha}^{9}$ là $34 \%$. Dâuu hiệu mạch máu mạc treo ngấm thuốc kém là dấu hiệu có độ đặc hiệu $100 \%$ trong dự báo thiếu máu thành ruột nhưng có độ nhạy thấp $23,8 \%$, thấp hơn so với nghiên cứu trước đóo. Dấu hiệu dày thành quai ruột $>2 \mathrm{~mm}$ có độ nhạy $71,4 \%$ cao hơn so với phẩn tích tổng hợp của Millet ${ }^{8}$ là $43 \%$ nhưng độ đặc hiệu thấp do chúng tôi chọn $2 \mathrm{~mm}$ là mốc xác định dày thành quai ruột. Dấu hiệu hình bia có độ nhạy, độ đặc hiệu trong dự báo thiếu máu thành ruột lần lượt là $57 \% ; 73,7 \%$ tương đồng với nghiên cứu của Nakashima ${ }^{6}$ là $41 \% ; 75 \%$ và thường gợi ý quai ruột thiếu máu có khả năng hồi phục được. 


\section{KẾT LUÂN}

Tắc ruột quai đóng là một cấp cứu ngoại khoa. Vì vậy, điều quan trọng là phải nhận diện được các dấu hiệu trên CLVT của tắc ruột quai đóng bao gồm dấu hiệu có ít nhất hai điểm chuyển tiếp, mỏ chim, quai ruột hình chữ $U / C$, dấu hiệu "vành tia", cuộn xoáy và vị trí bất thường của quai ruột. Thành ruột ngấm thuốc kém và mach máu mạc treo ngấm thuốc kém là các dấu hiệu chỉ gợi ý cho thiếu máu thành ruột.

\section{TÀl LIÊU THAM KHẢO}

1. Hà Văn Quyết. Bài giảng bệnh học tắc ruột. Nhà Xuất Bản Y Hoc

2. Balthazar EJ, Birnbaum BA, Megibow AJ, Gordon RB, Whelan CA, Hulnick DH. Closedloop and strangulating intestinal obstruction: CT signs. Radiology. 1992;185(3):769-775.

3. Maglinte $D$, Herlinger $H$, Nolan $D$ (1991) Radiologic features of closed loop obstruction: analysis of 25 confirmed cases. Radiology 179:383-387
4. Elsayes KM, Menias CO, Smullen TL, Platt JF Closed-Loop Small-Bowel Obstruction: Diagnostic Patterns by Multidetector Computed Tomography. J Comput Assist Tomogr. 2007;31(5):5.

5. Makar RA, Bashir MR, Haystead $C M$, et al. Diagnostic performance of MDCT in identifying closed loop small bowel obstruction. Abdom Radiol. 2016;41(7):1253-1260.

6. Nakashima $K$, Ishimaru $H$, Fujimoto $T$, et al. Diagnostic performance of CT findings for bowel ischemia and necrosis in closed-loop small-bowel obstruction. Abdom Imaging. 2015;40(5):10971103.

7. Nguyễn Văn Khánh. Đánh giá giá trị cuẩ cắt lớp vi tính đa dãy trong chẩn đoán một số nguyên nhân tắc ruột cơ giới. Đại Học Y Hà Nội; 2019

8. Millet I, Taourel P, Ruyer A, Molinari N. Value of CT findings to predict surgical ischemia in small bowel obstruction: A systematic review and metaanalysis. Eur Radiol. 2015;25(6):1823-1835.

9. Ha H. K., Park C. H., Kim S. K., et al. (1993), "CT analysis ofintestinal obstruction due to adhesions: early detection of strangulation". JComput Assist Tomogr, 17 (3), pp. 386-389.

\section{ĐĂC ĐIỂM LÂM SÀNG RỐI LOẠN TRẦM CẢM Ở NGƯờI BÊ̂NH VẢY NẾN ĐIỀU TRI TẠI BỆNH VIỆN DA LIỄU TRUNG ƯO'NG}

\section{TÓM TẮT}

Đặt vấn đê: Trâm cảm là bệnh lý đi kèm thường găp ở người bệnh vảy nến, trâm cảm làm triệu chứng vày nến nă̆ng hơnn, biến chứng xảy ra nhiều hơn, giảm tuân thủ điều trị, tăng nguy cơ tử vong và tư sát trên người bệnh. Mục tiêu nghiên cứu: Mô tả đặc điểm lâm sàng rối loạn trầm cảm ở người bệnh vảy nến điều trị nội trú tại bệnh viện Da Liễu Trương Ương. Đối tượng và phướng pháp nghiên cứu: Nghiên cứu mô tả cắt ngang 122 người bệnh vảy nến điều trị tai bênh viên Da Liểu Trung Ương từ tháng 08/2020 đến tháng 08/2021. Kết quả: Đối tượng nghiên cứu bệnh nhân nam nhiêu hơn bệnh nhân nữ chiếm tỷ lệ $68,9 \%$ so với nữ là $31,1 \%$; độ tuổi trung bình $51,02 \pm$ 15,79 ; nơi sinh sống chủ yếu ở nông thôn $(55,7 \%)$; trình độ học vấn trung học phổ thông (41\%). Có $26,2 \%$ người bệnh có rối loạn trầm cảm theo ICD 10 , trong đó trầm cảm nhẹ chiếm 13,9\%; triệu chứng khởi phát hay gặp nhất tự ti $(46,9 \%)$; trong các triêu chứng đặc trưng đặc trưng của trâm cảm, khí sắc

\footnotetext{
${ }^{1}$ Đại học Y Hà Nội

2Viện sức Khỏe Tâm thần, Bệnh viện Bạch Mai

Chịu trách nhiệm chính: Phạm Thị Thu Hà

Email: hajapan94@gmail.com

Ngày nhận bài: 26.7.2021

Ngày phản biện khoa học: 27.9.2021

Ngày duyệt bài: 6.10.2021
}

\section{Phạm Thị Thu Hà', Nguyễn Doãn Phương ${ }^{2}$, Nguyễn Văn Tuấn ${ }^{1,2}$, Lê Công Thiện ${ }^{1,2}$,}

trâm là hay gặp nhất $(96,9 \%)$; trong các triệu chứng phổ biến của trầm cảm, hay gặp nhất là giảm tính tự trọng và lòng tự ti $(100 \%)$ và rối loạn giấc ngủ $(90,6 \%)$. Kết luận: Trầm cảm thường khởi phát đâu tiên bởi tự ti về bản thân. Triệu chứng đặc trưng hay gặp nhất là khí sắc trầm, triệu chứng phổ biến hay gặp là giảm sút tính tự trong, lòng tự tin và rối loạn giấc ngủ.

Tư khóa: trầm cảm, vảy nến, đặc điểm lâm sàng.

\section{SUMMARY}

\section{CLINICAL FEATURES OF DEPRESSION IN PATIENT WITH PSORIASIS TREATMENT AT NATIONAL DERMATOLOGY HOSPITAL}

Background: Depression is a common comorbid disease in psoriasis patients, which adversely affects the patients' physical and mental aspects. Depression makes psoriasis symptoms worse, decreases treatment adherence, increases complications rates, mortality and suicide rates. Objectives: To describe clinical features of depression in patients with psoriasis. Subjects and research methods: A cross-sectional descriptive study of 122 patients with psoriasis who were treated at the National Hospital of Dermatology from August 2020 to August 2021. Results: Male and female ratio is about 2:1; average age is $51 \pm 15.79$; living in rural areas $55.7 \%$; upper secondary education level - $41 \%$. Main clinical features: $26.2 \%$ of patients with depressive 